\title{
Dynamic role and importance of surrogate species for assessing potential adverse environmental impacts of genetically engineered insect-resistant plants on non-target organisms
}

\author{
Michael Wach $(\mathbb{D} \cdot$ Richard L. Hellmich • \\ Raymond Layton • Jörg Romeis • \\ Patricia G. Gadaleta
}

Received: 4 November 2015/ Accepted: 23 February 2016/Published online: 27 February 2016

(C) The Author(s) 2016. This article is published with open access at Springerlink.com

\begin{abstract}
Surrogate species have a long history of use in research and regulatory settings to understand the potentially harmful effects of toxic substances including pesticides. More recently, surrogate species have been used to evaluate the potential effects of proteins contained in genetically engineered insect resistant (GEIR) crops. Species commonly used in GEIR crop testing include beneficial organisms such as honeybees, arthropod predators, and parasitoids. The choice of appropriate surrogates is influenced by scientific factors such as the knowledge of the mode of action and the spectrum of activity as well as societal factors such as protection goals that assign value to
\end{abstract}

M. Wach ( $\square)$

Center for Environmental Risk Assessment, ILSI

Research Foundation, Washington, DC, USA

e-mail: mwach@ilsi.org

\section{R. L. Hellmich}

USDA-ARS, Corn Insects and Crop Genetics Research

Unit and Department of Entomology, Iowa State

University, Ames, IA, USA

R. Layton

DuPont Pioneer, Johnston, IA, USA

J. Romeis

Agroscope Reckenholz-Tänikon Research Station ART,

Zurich, Switzerland

P. G. Gadaleta

Biotechnology Directorate, Ministry of Agriculture,

Livestock and Fisheries, Buenos Aires, Argentina certain ecosystem services such as pollination or pest control. The primary reasons for using surrogates include the inability to test all possible organisms, the restrictions on using certain organisms in testing (e.g., rare, threatened, or endangered species), and the ability to achieve greater sensitivity and statistical power by using laboratory testing of certain species. The acceptance of surrogate species data can allow results from one region to be applied or "transported" for use in another region. On the basis of over a decade of using surrogate species to evaluate potential effects of GEIR crops, it appears that the current surrogates have worked well to predict effects of GEIR crops that have been developed (Carstens et al. GM Crops Food $5: 1-5,2014)$, and it is expected that they should work well to predict effects of future GEIR crops based on similar technologies.

Keywords Surrogate species - Genetically engineered insect resistance $\cdot$ Environmental risk assessment

\section{Introduction}

Surrogate species are those used to represent or substitute for other species. Surrogate species have a long history of use to evaluate potentially harmful effects of toxic substances. For example, beginning in the early 1900s mice and small birds were used in coal 
mines to detect carbon monoxide and thus improve worker safety (Acott et al. 1999; USDOL 2015). Other animal models came into use in laboratory testing after Trevan proposed comparing the toxicity of substances using LC50 values to predict effects on humans (Trevan 1927). Animal models, including various in vitro models, have been used for decades as surrogates for humans to assess the safety of pharmacology products and medical treatments. The first use of surrogates in ecological studies is attributed to Moore who conducted research on the environmental health of heath areas in the United Kingdom (Moore 1962). He used ten species (two plants, four insects, two lizards, and two birds) to evaluate the effect of land use changes. Over time various surrogate species (e.g., bobwhite quail, rainbow trout, water flea) began to be used successfully to provide environmental risk assessors with data to help make regulatory decisions regarding pesticides and other chemicals (Urban and Cook 1986).

Interest in protecting the ecological systems within agricultural systems began as a minor element of pest control in the 1940s, which then, during the late 1960s, developed into the practice of integrated pest management (IPM) with emphasis on preserving populations of beneficial insects (Ehler 2006). Testing systems for beneficial arthropod predators and parasites based on surrogates were developed (Croft and Strickler 1983; Hassan and Vogt 2006), however, there were no standardized protocols. In 1974 the International Organisation for Biological Control (IOBC) began the development of standardized tests for beneficial arthropods and introduced a tiered approach, with iterative tests, selection criteria for test species, and methods to interpret data (Hassan and Vogt 2006).

Genetically engineered insect resistant (GEIR) crops were developed in the 1990s and offered effective control over various insect pests. In 2014, GEIR crops were cultivated in 28 countries on 181 million ha worldwide (James 2014). Prior to cultivation in each country, these crops pass through a regulatory evaluation-including an environmental risk assessment. This paper provides a review of the use of surrogate species in the context of the environmental risk assessment (ERA) of GEIR crops. The first section provides an overview of the use of arthropod surrogates for the ERA of synthetic chemical pesticides and control agents. The second section describes how the existing methods using arthropod surrogates were applied to the evaluation of potential non-target effects of GEIR crops. Finally, the paper proposes ways to broaden the utility and transportability of environmental risk assessments informed by data from surrogate species testing in order to improve the risk assessment process, prevent the generation of duplicative data, and increase the consistency and efficiency of regulatory decision making.

\section{Surrogates in ERA for conventional pesticides}

Most of the early efforts to test effects of pesticides on beneficial non-target arthropods were made in Europe. In 1974 the West Palaearctic Regional Section (WPRS) of the IOBC started to develop standardized tests for beneficial arthropods (Hassan and Vogt 2006). The motivation of the IOBC/WPRS efforts for establishing surrogates for non-target testing was to identify pesticides with limited adverse effects on beneficial arthropods under field conditions that would be compatible with IPM and integrated crop management (ICM) practices. The Pesticides and Beneficial Organisms Working Group of the IOBC/WPRS evaluated which surrogate species would be most useful and ultimately developed standard tests for nearly two dozen natural enemy species. The joint testing efforts initially focused on laboratory tests but then expanded to include semi-field and field procedures (Hassan et al. 1985, 1987; Croft 1990). The IOBC/WPRS efforts created a foundation for non-target arthropod (NTA) testing, and ERA requirements for European registration were defined in three international multi-stakeholder workshops: ESCORT 1 (European standard characteristics of non-target arthropod regulatory testing; (Barrett et al. 1994)), ESCORT 2 (Candolfi et al. 2001) and ESCORT 3 (Alix et al. 2012). Many of these protocols for evaluating non-target effects of arthropod control substances and have been used by regulators worldwide.

Standard procedures for regulatory testing of pesticides were agreed upon at the ESCORT 1 workshop. This included the application of a hierarchical, tiered testing scheme and the request of NTA data from four to six species including two species known to be particularly sensitive (a predatory mite, Typhlodromus pyri and an aphid parasitoid, Aphidius rhopalosiphi), and up to four crop-relevant species that are 
representative of ground- and foliage-dwelling predators and amenable to laboratory testing (Barrett et al. 1994). This marked the start of a systematic evaluation of the non-target effects of pesticides, and several standardized and ring-tested laboratory test methods were subsequently published (Candolfi et al. 2000). ESCORT 2 built upon ESCORT 1 and resulted in two major studies that evaluated the sensitivity of arthropods representing many NTA species across multiple orders to nearly 100 different pesticides (Candolfi et al. 1999; Heimbach et al. 2000). The species were selected based on commercial availability, amenability to testing in the laboratory, availability of validated test protocols, provision of sufficient phylogenetic and functional diversity, and representation of species that are present in agricultural fields and exposed to pesticides (Barrett et al. 1994; Candolfi et al. 2001). ESCORT 3 shifted the focus from in-crop risk assessment to off-crop areas, thus reaching the issue of biodiversity (Alix et al. 2012). One conclusion from the workshop was that the information and recommendations contained in current guidance documents produced during ESCORT 1 and 2 are applicable for conducting ERA for off-crop areas. In addition to the NTA guidance developed by the ESCORT workshops, many regulatory jurisdictions also require testing of honeybees. This is due to new pesticide regulations (European Commission 2009) based on biodiversity protection. Since the value of wild bees is of increasing interest in recent years, testing has been expanded to Bombus spp. and solitary bees (EFSA 2013). Similarly, surrogates that contribute to ecological functions in the soil have been proposed. For early tier studies in the laboratory these include the springtail Folsomia candida, the predatory mite Hypoaspis aculeifer, and dung beetles (Römbke 2006).

\section{Surrogates in ERA for GEIR}

The successful development and use of NTA surrogates in predicting the potential effects of conventional pesticides in Europe has had a significant effect on the development of testing to evaluate potential environmental effects of GEIR crops. For example, an important criterion for selection of surrogate species was potential exposure in the field (Romeis et al. 2011). Surrogate species selected during the ESCORT process also could be used for testing associated with GEIR crops, although many of the tests developed during the ESCORT process were modified for use in testing pesticidal proteins in the laboratory: the ESCORT tests utilized contact or dermal exposure, GEIR testing required oral exposure. Criteria, such as availability of test organisms and protocols for testing and evaluating data were easily applied to selecting organisms for use in testing GEIRs. For example, test species commonly used for testing GEIR crops prior to cultivation approval in the United States include the earthworm and arthropod taxa including honeybees and three species of predators (from the orders Hemiptera, Coleoptera, usually ladybird beetles, Neuroptera, Hymenoptera, and Acarina) and parasitoids (from the orders of Diptera and Hymenoptera). The USEPA has recommended that testing should be performed on species from at least two of these groups; plus selection should take into account factors such as likelihood of exposure and phylogenetic relationship of test species to the target pest species (USEPA 1996). Phylogenetic relationships have been shown to be useful in the evaluation of possible adverse effects from insect resistance mediated by Bt proteins and double-stranded RNA (Romeis et al. 2009, 2013; Bachman et al. 2013). Lack of activity against a NTA surrogate species within the same order as the target species, such as Hymenoptera, provides assurance that species in more distantly related orders, such as Hemiptera, are also very unlikely to be affected. The need for testing is thereby reduced as the phylogenetic distance increases from the target spectrum. For exposure, lists of potentially exposed species will be similar to those already established for conventional pesticides.

In addition, knowledge about the mode of action of the compound and its spectrum of activity can inform the selection of species that are likely to be sensitive to the stressor of concern and thus provide the most rigorous test of the risk hypothesis. Other factors, such as the high value of certain ecosystem services, such as pollination by honeybees and decomposition by Collembola species (Romeis et al. 2013), also may help determine the selection of surrogates, even when there is no scientific reason to suspect harm from the stressor.

\section{Other considerations}

The risk assessment that precedes the commercial use of genetically engineered crops is guided by broad 
environmental policies and protection goals, such as the protection of biodiversity and sustainable agricultural production (Wolt et al. 2010; Gray 2012; GarciaAlonso and Raybould 2013). These policies and goals share common elements with those associated with the risk assessment of conventional pesticides. The selection of species data needed to evaluate the potential effects of GEIR crops requires the risk assessor to define the time period during which it should be protected, in order to translate broad environmental policies and protection goals into risk assessment operational goals (USEPA 2003; Gray 2012; Sanvido et al. 2012; Garcia-Alonso and Raybould 2013). This evaluation is done as part of problem formulation where, based on literature and inputs from experts, plausible links for both hazard and exposure are established between the stressor and protected entities.

There are three key reasons for using surrogates as part of the ERA process for GEIR crops. The first reason surrogates are used is the disruptive effect and cost of sampling and analysis: it is simply impossible to test and collect all species that are present in the receiving environment, and any attempt to do so would greatly disturb the agroecosystem and affect subsequent sampling. Thus, sampling methods are devised, and surrogate species are selected to represent the range of species potentially exposed to the particular environmental impact in question. The second reason surrogates are used is the case of assessing impacts to threatened or endangered species-even if these species could be reared in the laboratory, they are subject to certain legal restrictions. A third reason surrogates are used is that laboratory studies offer greater statistical power and endpoint sensitivity over field studies. Thus surrogate species are used to obtain information that can then be extrapolated to threatened and endangered species.

Given that it is impossible to test all non-target species potentially exposed to a control product, test species must be selected that represent the range of species potentially exposed to the pesticide (Raybould et al. 2011; Romeis et al. 2013). However, many organisms are not amenable to laboratory testing, usually because validated protocols and standardized diets are not available to rear and maintain consistent populations of organisms. Validated test protocols should be available for the species to ensure that the data obtained from the experiments are robust and reliable.
Tiered testing has been shown to be effective for identifying adverse direct effects on non-target organisms and establishing a lack of environmental harm arising from cultivation of GEIR crops, including those expressing Bt proteins (Duan et al. 2010). Extensive Tier I and Tier II studies suggest that, across many $\mathrm{Bt}$ transformation events and GEIR crop species, field studies are rarely, if ever, necessary to conclude a lack of ecologically relevant direct effects on NTA (Romeis et al. 2006; Marvier et al. 2007; Wolfenbarger et al. 2008; Naranjo 2009; Comas et al. 2014). The utility of early tier tests using surrogate species for conservatively predicting field effects has enabled regulatory agencies such as the USEPA to drop confirmatory field studies that were a condition of registrations during the first decade of commercial development of GEIR crops (USEPA 2014).

The use of surrogate species in tiered testing means that the results may be applicable, or transportable, to be used in risk assessments across countries and GEIR crops (Romeis et al. 2009; Raybould and Quemada 2010). This is particularly the case with early tier studies conducted under controlled conditions. The transportability of data from early-tier tests is greatly enhanced if the test methods are robust and designed to meet the quality standards of regulatory authorities in those jurisdictions where the genetically engineered insect-resistant event may be released for cultivation (Romeis et al. 2011). The Cartagena Protocol on Biodiversity encourages the use of any relevant scientific evidence that informs the risk assessment process, including evidence developed out of the country (CBD 2000), and in practice, the same ecotoxicology studies of a specific test substance could be reviewed by multiple competent authorities as part of pre-market ERAs. In situations where semi-field or field studies (sometimes referred to as Tier III and IV) are needed to provide critical data to refine the risk assessment, careful selection of experimental endpoints based on surrogate species used in early tier tests can facilitate data transportability. This can be relatively straightforward since most countries have protection goals that apply to a common set of valued ecological functions (e.g., pollination, biological control, etc.), and there is no scientific rationale to support the idea that NTA susceptibility is linked to political boundaries. Results from field experiments that directly measure these ecological functions can inform ERAs in the country where the study was conducted 
and also in other countries with similar receiving environments (Garcia-Alonso et al. 2014).

In addition to surrogate species, there are also other surrogate measures that can be applied. Direct measures of ecological functions are possible alternatives to field collections of arthropods. For example, methods are established to assess ecosystem services such as biological control, pollination, and decomposition of organic matter. Data from egg cards or sentinel hosts provide surrogate data for actual field effects (Luck et al. 1988). Seed set in potted plants has been used as a surrogate for pollination response (Jarlan et al. 1997). Decomposition of GE plant materials in litter bags has been used to provide surrogate data in both terrestrial and aquatic systems (Hönemann et al. 2008; Axelsson et al. 2010).

Surrogate species will continue to be used in future assessments of GEIR crops even as ERA processes change. An ecosystem services approach based on concepts in the Millennium Ecosystem Assessment (MEA) (Millenium Ecosystem Assessment 2005) has been proposed for the regulation of plant protection products (Nienstedt et al. 2012). Ecosystem services also have been proposed for use in ERA for GEIR crops by the European Food Safety Authority (Devos et al. 2015). Partitioning of common protection goals, such as biodiversity and sustainable agriculture, into ecosystem services helps define endpoints for risk assessment including: (1) entities to be protected from harm, (2) valued attributes of these entities (e.g., abundance or function), (3) unit of protection (individuals, populations, or functions), (4) spatial scale of protection (e.g., crop, non-agricultural habitats), and (5) temporal scale or protection (e.g., present or following cropping season) (Sanvido et al. 2012; Garcia-Alonso and Raybould 2013). Such an approach is useful to build links between regulated products and protected entities (i.e., defining pathways to harm) and to develop testable risk hypotheses (Gray 2012; Garcia-Alonso and Raybould 2013). Formulated risk hypotheses can then be tested within a tiered framework that moves from laboratory or early-tier tests, to more complex (higher tier) experiments, when necessary, which evaluate risks under more realistic exposure conditions (Hill and Sendashonga 2003; GarciaAlonso et al. 2006; Romeis et al. 2008). The results from early tier testing are regarded as highly conservative, i.e., if an NTA is not affected under confined and controlled laboratory exposure conditions, the
NTA is unlikely to be affected in the field. Through problem formulation and selection of appropriate surrogate species, the tiered testing process can be used to evaluate the potential effects on ecosystem services.

\section{Conclusions and recommendations}

For over 50 years surrogate species have been used extensively to assess the effects of environmental stressors on various organisms. Although surrogate species testing may have originally been adopted for the simple reason that not all non-target organisms could be tested, the value of surrogate species in environmental risk assessment has been recognized globally and is now standard practice for the generation of ERA data. This is because surrogate species testing can generate consistent data, of high statistical power, that accurately predicts the environmental impacts of a given stressor. Data regarding impacts from GEIR crops on surrogate species are informing regulatory decision making in every country that has considered the commercial deployment of these crops, and the track record of safe use of GE crops demonstrates the value and utility of surrogate species tests.

However, the fact remains that there continues to be disharmony among national regulatory systems, resulting in needless duplication of environmental safety testing and worse, the generation of incongruent conclusions regarding the safety of GEIR crops. Given the volume of NTO effects data generated through the use of surrogate species and the depth of analysis to which these data have been subjected, the following conclusions support the transportability and the acceptance of these available data, as well as new data to be collected, using surrogate species for the ERA of new GEIR.

1. Current surrogates have worked well, based on a review of surrogate species tests and their ability to predict field level effects.

2. The surrogate species approach also should work well for newly developed GEIR using Bt proteins.

3. There does not appear to be a need for countries to perform NTA assessments on novel, local species simply because they are local, if an appropriate surrogate has already been tested. 
4. Standards/criteria/protocols for laboratory testing using existing and newly identified surrogate species should be developed, validated, disseminated and used so that results are transportable.

Open Access This article is distributed under the terms of the Creative Commons Attribution 4.0 International License (http:// creativecommons.org/licenses/by/4.0/), which permits unrestricted use, distribution, and reproduction in any medium, provided you give appropriate credit to the original author(s) and the source, provide a link to the Creative Commons license, and indicate if changes were made.

\section{References}

Acott C, Haldane JS, Haldane JBS, Hill L, Siebe A (1999) A brief résumé of their lives. South Pacific Underw Med Soc J 29:161-165

Alix A, Bakker F, Barrett K et al (2012) ESCORT 3. Linking non-target arthropod testing and risk assessment with protection goals, Pensacola

Axelsson EP, Hjältén J, LeRoy CJ et al (2010) Can leaf litter from genetically modified trees affect aquatic ecosystems? Ecosystems 13:1049-1059. doi:10.1007/s10021-010-9373-y

Bachman PM, Bolognesi R, Moar WJ et al (2013) Characterization of the spectrum of insecticidal activity of a doublestranded RNA with targeted activity against Western corn rootworm (Diabrotica virgifera virgifera LeConte). Transgenic Res 22:1207-1222. doi:10.1007/s11248-0139716-5

Barrett KL, Grandy N, Harrison EG et al (1994) Guidance document of regulatory testing procedures for pesticides with non-target arthropods. In: ESCORT Workshop (European standard characteristics of non-target arthropod regulatory testing). Society of Environmental Toxicology and Chemistry, Brussels, Belgium

Candolfi MP, Bakker F, Cañez V et al (1999) Sensitivity of nontarget arthropods to plant protection products: could Typhlodromus pyri and Aphidius spp. be used as indicator species? Chemosphere 39:1357-1370. doi:10.1016/S00456535(98)00489-5

Candolfi MP, Blûmel S, Forster R et al (2000) Guidelines to evaluate side-effects of plant protection products to nontarget arthropods. Ghent, Belgium

Candolfi MP, Barrett KL, Campbell P et al (2001) Guidance document on regulatory testing and risk assessment procedures for plant protection products with non-target arthropods. In: ESCORT2 Workshop (European standard characteristics of non-target arthropods)

CBD (2000) Cartagena Protocol on Biosafety. Conv Biol Divers http://bch.cbd.int/protocol/

Carstens K, Cayabyab B, De Schrijver A et al (2014) Surrogate species selection for assessing potential adverse environmental impacts of genetically engineered insect-resistant plants on non-target organisms. GM Crops Food 5:1-5

Comas C, Lumbierres B, Pons X, Albajes R (2014) No effects of Bacillus thuringiensis maize on nontarget organisms in the field in southern Europe: a meta-analysis of 26 arthropod taxa. Transgenic Res 23:135-143. doi:10.1007/s11248013-9737-0

Croft BA (1990) Arthropod biological control agents and pesticides. Wiley, New York

Croft BA, Strickler K (1983) Natural enemy resistance to pesticides: documentation, characterization, theory, and application. In: Georghiou GP, Saito T (eds) Pest resistance to pesticides. Plenum Press, New York

Devos Y, Romeis J, Luttik R et al (2015) Optimising environmental risk assessments. EMBO Rep 16(9):1060-1063

Duan JJ, Lundgren JG, Naranjo S, Marvier M (2010) Extrapolating non-target risk of $\mathrm{Bt}$ crops from laboratory to field. Biol Lett 6:74-77

EFSA (2013) Guidance on the risk assessment of plant protection products on bees (Apis mellifera, Bombus spp. and solitary bees). EFSA J 11:3295

Ehler LE (2006) Integrated pest management (IPM): definition, historical development and implementation, and the other IPM. Pest Manag Sci 62:787-789. doi:10.1002/ps.1247

European Commission (2009) Regulation (EC) No 1107/2009 of the European Parliament and of the Council of 21 October 2009 concerning the placing of plant protection products on the market and repealing Council Directives 79/117/EEC and 91/414/EEC

Garcia-Alonso M, Raybould A (2013) Protection goals in environmental risk assessment: a practical approach. Transgenic Res. doi:10.1007/s11248-013-9760-1

Garcia-Alonso M, Jacobs E, Raybould A et al (2006) A tiered system for assessing the risk of genetically modified plants to non-target organisms. Environ Biosafety Res 5:57-65. doi:10.1051/ebr:2006018

Garcia-Alonso M, Hendley P, Bigler F et al (2014) Transportability of confined field trial data for environmental risk assessment of genetically engineered plants: a conceptual framework. Transgenic Res. doi:10.1007/s11248014-9785-0

Gray A (2012) Problem formulation in environmental risk assessment for genetically modified crops: a practitioner's approach. Collect Biosaf Rev 6:10-65

Hassan SA, Vogt H (2006) Working group pesticides and beneficial organisms (1974-present). In: Boller EF, Lenteren JC van, Delucchi V (eds) International Organization for Biological Control of Noxious Animals and Plants (IOBC): history of the first 50 years (1956-2006). pp 221-228

Hassan SA, Bigler F, Blaisinger P et al (1985) Standard methods to test the side-effects of pesticides on natural enemies of insects and mites developed by the IOBC/WPRS Working Group "Pesticides and Beneficial Organisms". EPPO Bull 15:214-255. doi:10.1111/j.1365-2338.1985.tb00224.x

Hassan SA, Albert R, Bigler F et al (1987) Results of the third joint pesticide testing programme by the IOBC/WPRSWorking Group "Pesticides and Beneficial Organisms". J Appl Entomol 103:92-107. doi:10.1111/j.1439-0418. 1987.tb00963.x

Heimbach U, Wehling A, Barrett KL et al (2000) A method for testing effects of plant protection products on spiders of the genus Pardosa (Araneaa, Lycosidae) under laboratory conditions. In: Candolf MP, Blumel S, Forster FM, Bakker C, Grimm SA, Hassan U, Heimbach MA, Mead-Briggs B, Reber R, Schmuck HV (eds) Guidelines to evaluate side- 
effects of plant protection products to non-target arthropods. International Organization for Biological and Integrated Control of Noxious Animals and Weeds, West Palearctic Regional Section (IOBC/WPRS), Ghent

Hill RA, Sendashonga C (2003) General principles for risk assessment of living modified organisms: lessons from chemical risk assessment. Environ Biosafety Res 2:81-88. doi:10.1051/ebr:2003004

Hönemann L, Zurbrügg C, Nentwig W (2008) Effects of Bt-corn decomposition on the composition of the soil meso- and macrofauna. Appl Soil Ecol 40:203-209. doi:10.1016/j. apsoil.2008.04.006

James C (2014) Global status of commercialized Biotech/GM crops: 2014. Ithaca, NY

Jarlan A, De Oliveira D, Gingras J (1997) Pollination by Eristalis tenax (Diptera: Syrphidae) and seed set of greenhouse sweet pepper. J Econ Entomol 90:1646-1649. doi:10.1093/jee/90.6.1646

Luck RF, Shepard BM, Kenmore PE (1988) Experimental methods for evaluating arthropod natural enemies. Annu Rev Entomol 33:367-389

Marvier M, McCreedy C, Regetz J, Kareiva P (2007) A metaanalysis of effects of $\mathrm{Bt}$ cotton and maize on nontarget invertebrates. Science (80-) 316:1475-7. doi: 10.1126/ science. 1139208

Millenium Ecosystem Assessment (2005) Millenium Ecosystem Assessment Synthesis Report. Washington, DC

Moore NW (1962) The heaths of Dorset and their conservation. J Ecol 50:369-391

Naranjo SE (2009) Impacts of Bt crops on non-target invertebrates and insecticide use patterns. CAB Rev Perspect Agric Vet Sci Nutr Nat Resour 4:1-11

Nienstedt KM, Brock TCM, van Wensem J et al (2012) Development of a framework based on an ecosystem services approach for deriving specific protection goals for environmental risk assessment of pesticides. Sci Total Environ 415:31-38. doi:10.1016/j.scitotenv.2011.05.057

Raybould A, Quemada H (2010) Bt crops and food security in developing countries: realised benefits, sustainable use and lowering barriers to adoption. Food Secur 2:247-259

Raybould A, Caron-Lormier G, Bohan DA (2011) Derivation and interpretation of hazard quotients to assess ecological risks from the cultivation of insect-resistant transgenic crops. J Agric Food Chem 59:5877-5885

Römbke J (2006) Tools and techniques for the assessment of ecotoxicological impacts of contaminants in the terrestrial environment. Hum Ecol Risk Assess 12:84-101. doi:10. 1080/10807030500430427
Romeis J, Meissle M, Bigler F (2006) Transgenic crops expressing Bacillus thuringiensis toxins and biological control. Nat Biotechnol 24:63-71

Romeis J, Bartsch D, Bigler F et al (2008) Assessment of risk of insect-resistant transgenic crops to nontarget arthropods. Nat Biotechnol 26:203-208

Romeis J, Lawo N, Raybould A (2009) Making effective use of existing data for case-by-case risk assessments of genetically engineered crops. J Appl Entomol 133:571-583. doi:10.1111/j.1439-0418.2009.01423.x

Romeis J, Hellmich RL, Candolfi MP et al (2011) Recommendations for the design of laboratory studies on non-target arthropods for risk assessment of genetically engineered plants. Transgenic Res 20:1-22

Romeis J, Raybould A, Bigler F et al (2013) Deriving criteria to select arthropod species for laboratory tests to assess the ecological risks from cultivating arthropod-resistant genetically engineered crops. Chemosphere 90:901-909

Sanvido O, Romeis J, Gathmann A et al (2012) Evaluating environmental risks of genetically modified crops: ecological harm criteria for regulatory decision-making. Environ Sci Policy 15:82-91

Trevan JW (1927) The error of determination of toxicity. Proc R Soc 101:483-514

Urban DJ, Cook NJ (1986) Hazard evaluation division, standard evaluation procedure: ecological risk assessment. United States Environmental Protection Agency, Washington

USDOL (2015) Canaries. Mine Saf. Heal. Adm. Canar. http:// www.msha.gov/CENTURY/canary/canary.asp. Accessed 1 Jul 2015

USEPA (1996) Microbial pesticide test guidelines, OPPTS 885.4000: background for nontarget organisms testing of microbial pest control agents. United States Environmental Protection Agency, Washington

USEPA (2003) Generic ecological assessment endpoints (GEAEs) for ecological risk assessment. Washington

USEPA (2014) Introduction to biotechnology regulation for pesticides. http://www.epa.gov/pesticides/biopesticides/re gtools/biotech-reg-prod.htm\#nontarget. Accessed 3 Sep 2015

Wolfenbarger LL, Naranjo SE, Lundgren JG et al (2008) Bt crop effects on functional guilds of non-target arthropods: a meta-analysis. PLoS ONE 3:1-11

Wolt JD, Keese P, Raybould A et al (2010) Problem formulation in the environmental risk assessment for genetically modified plants. Transgenic Res 19:425-436. doi:10.1007/ s11248-009-9321-9 